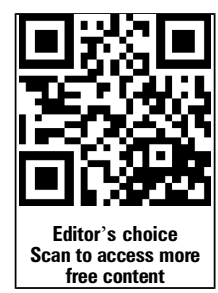

free content

\title{
Endovascular coiling versus parent artery occlusion for treatment of cavernous carotid aneurysms: a meta-analysis
}

\author{
Zaahir A Turfe, ${ }^{1}$ Waleed Brinjikji, ${ }^{2}$ Mohammad H Murad ${ }^{3}{ }^{3}$ Giuseppe Lanzino, ${ }^{2,4}$ \\ Harry J Cloft, ${ }^{2,4}$ David F Kallmes ${ }^{2,4}$
}

${ }^{1}$ College of Human Medicine, Michigan State University, East Lansing, Michigan, USA ${ }^{2}$ Department of Radiology, Mayo Clinic, Rochester, Minnesota, USA

${ }^{3}$ Center for Science of Healthcare Delivery, Mayo Clinic, Rochester, Minnesota, USA ${ }^{4}$ Department of Neurosurgery, Mayo Clinic, Rochester, Minnesota, USA

\section{Correspondence to} Dr W Brinjikji, Mayo Clinic, OL 1-115, 200 SW First Street, Rochester, MN 55905, USA; brinjikji.waleed@mayo.edu

Received 5 January 2014 Revised 1 March 2014 Accepted 3 March 2014 Published Online First 21 March 2014

\section{ABSTRACT}

Background and purpose Endosaccular coil embolization and parent artery occlusion (PAO) are established endovascular techniques for treatment of cavernous carotid aneurysms. We performed a systematic review of published series on endovascular treatment of cavernous carotid aneurysms to determine outcomes and complications associated with endovascular coiling and PAO of cavernous carotid artery aneurysms.

Methods In September 2013, we conducted a computerized search of MEDLINE and EMBASE for reports on endovascular treatment of intracranial cavernous carotid aneurysms from January 1990 to August 2013. Comparisons were made in periprocedural complications and outcomes between coiling and PAO patients who did not receive bypass. Event rates were pooled across studies using random effects metaanalysis.

Results 20 studies with 509 patients and 515 aneurysms were included in this systematic review. Aneurysm occlusion rates at $>3$ months after operation were significantly higher in the PAO without bypass group $(93.0 \%, 95 \% \mathrm{Cl} 86.0$ to 97.0$)$ compared with the coiling group $(67.0 \%, 95 \% \mathrm{Cl} 55.0$ to 77.0$)$ $(p<0.01)$. Retreatment rates were significantly lower in the PAO without bypass group $(6.0 \%, 95 \% \mathrm{Cl} 2.0$ to $12.0)$ compared with the coiling group $(18.0 \%, 95 \% \mathrm{Cl}$ 12.0 to 26.0$)(p=0.01)$. Coiling patients had a similar morbidity rate $(3.0 \%, 95 \% \mathrm{Cl} 2.0$ to 6.0$)$ compared with PAO without bypass patients $(7.0 \%, 95 \% \mathrm{Cl} 3.0$ to 12.0) $(p=0.13)$. Coiling patients had a similar mortality rate $(0.0 \%, 95 \% \mathrm{Cl} 0.0$ to 6.0$)$ compared with PAO without bypass patients $(4.0 \%, 95 \% \mathrm{Cl} 1.0$ to 9.0$)$ ( $p=0.68$ ).

Conclusions Evidence from non-comparative studies suggests that traditional endovascular options are highly effective in treating cavernous sinus aneurysms. PAO is associated with a higher rate of complete occlusion. Periprocedural morbidity and mortality rates are not negligible, especially in patients receiving PAO.

\section{INTRODUCTION}

Aneurysms of the cavernous carotid artery (CCA) CrossMark To cite: Turfe ZA, Brinjikji W, Murad MH, et al. J Neurolntervent Surg 2015;7:250-255. are associated with mass effect on adjacent cranial nerves while their risk of rupture with ensuing direct carotid cavernous fistulas or life threatening subarachnoid hemorrhage (SAH) is low. ${ }^{1-3}$ Because of the complexity of surgical treatment, endovascular techniques have emerged as the preferred therapy for treatment of symptomatic CCA aneurysms. Endosaccular coil embolization and parent artery occlusion (PAO) are established endovascular techniques for the treatment of carotid cavernous aneurysms. However, in the past few years, flow diversion has emerged as a newer technique for the treatment of these aneurysms although there are no definitive data supporting its superior safety and efficacy over more traditional techniques. A number of case series and retrospective studies have assessed the efficacy of endovascular techniques, such as endovascular carotid occlusion and endosaccular coiling, in treating CCA aneurysms. ${ }^{4}{ }^{5} \mathrm{~A}$ common limitation in most studies has been the limited number of patients. We sought to perform a systematic review to compare outcomes of endovascular carotid artery occlusion and endosaccular coiling in the treatment of ruptured and unruptured carotid cavernous aneurysms. Given the recent interest in the application of flow diversion to CCA aneurysms, these data provide an important benchmark against which the results of flow diversion can be assessed.

\section{METHODS}

In September of 2013, we performed a computerized MEDLINE and EMBASE search of the literature from January 1990 to August 2013 for reports of endovascular embolization of cavernous carotid aneurysms by using the keywords 'cavernous carotid artery', 'intracranial aneurysm', 'endovascular', 'coil', 'embolization', 'occlusion', and 'sacrifice' in both 'AND' and 'OR' combinations. Identified studies from the MEDLINE search were then further evaluated for inclusion in the systematic review. We also searched references from multiple articles to find any additional series on endovascular treatment of cavernous carotid aneurysms not found in our initial literature search. Inclusion criteria were the following: (1) studies reporting a consecutive series of cavernous carotid aneurysms (>5 patients), (2) studies reporting angiographic and/or clinical outcomes following treatment, and (3) studies stratifying outcomes by treatment modality. Studies reporting on patients treated with bypass in conjunction with endovascular $\mathrm{PAO}$ were also considered but patients receiving bypass were evaluated in a separate analysis. Exclusion criteria included the following: (1) studies reporting five or less patients, (2) studies reporting outcomes of endosaccular balloon embolization (non-coil embolization), (3) studies reporting endovascular occlusion of vessels other than the internal carotid 
artery and (4) studies in languages other than English. Patients with traumatic carotid cavernous fistulas (CCFs) and pseudoaneurysms were excluded.

Each study was analyzed to collect the following variables: (1) perioperative (procedure related) morbidity, (2) perioperative stroke (both clinical and radiographic), (3) perioperative hemorrhage, (4) perioperative mortality, (5) patient presentation, (6) aneurysm retreatment, (7) long term (>3 month) occlusion rate, and (8) improvement in mass effect. The perioperative period was defined as $<30$ days after operation. Outcomes were compared across two treatment groups: (1) endovascular coiling (including stent assisted coil patients) and (2) endovascular PAO (excluding patients who received bypass). Patients treated with endovascular PAO in conjunction with bypass were excluded from the comparative analysis in order to allow for direct comparisons between patients receiving endovascular only treatments. Two additional subgroup analyses were performed: (1) a subgroup analysis comparing outcomes of stent assisted and non-stent assisted coiling and (2) a second subgroup analysis of patients treated with bypass in conjunction with endovascular PAO.

\section{Statistical analysis}

We estimated from each study the cumulative incidence (event rate) and 95\% CI for each outcome. Event rates were pooled across studies using random effects meta-analysis. ${ }^{6}$ Subgroup effects were evaluated using an interaction test, as described by Altman. ${ }^{7}$ Comparisons were made between the coiling and PAO without bypass groups as well as between stent assisted and non-stent assisted coiling groups. Outcomes of the PAO with bypass group were evaluated separately due to the small number of patients. Heterogeneity across studies was evaluated using the $\mathrm{I}^{2}$ statistic. $^{8}$

\section{RESULTS}

Search results

MEDLINE and EMBASE searches yielded 495 articles; of these, 408 were excluded after reading the abstract alone, 39 additional studies were excluded for not meeting the inclusion criteria of $>5$ patients, eight studies were excluded for reporting endosaccular balloon occlusion rather than coil embolization, 19 studies were excluded because they reported on traumatic CCFs or post-traumatic pseudoaneurysms, and two studies were excluded as they did not stratify outcomes by PAO and coil embolization. Twenty articles met our inclusion criteria. All studies were retrospective case series. Thirteen studies included patients who underwent endosaccular coiling and 10 studies included patients who underwent PAO. Seven studies included patients who received stent assisted coiling. The smallest study had six patients and the largest study had 113 patients. A total of 509 patients with 515 aneurysms were included in the current analysis. A summary of the included studies is provided in table 1.

\section{Patient presentation and treatment}

Seventy-seven per cent of patients (95\% CI 65.0 to 86.0 ) presented with cranial nerve deficits, $7.0 \%$ of patients $(95 \%$ CI 5.0 to 10.0) presented with $\mathrm{SAH}$, and $7.0 \%$ of patients ( $95 \%$ CI 5.0 to 9.0) presented with CCF. A total of 176 patients (37.1\%) were treated with $\mathrm{PAO}$ and 339 patients (62.9\%) were treated with endosaccular coiling. Stent assisted coiling was used in 131 cases (37.5\%). A total of 135 patients (76.7\%) had endovascular PAO without bypass and 41 patients $(23.3 \%)$ had endovascular PAO with bypass. Table 2 describes the patient characteristics, patient presentations, and treatment modality used.

\section{Outcome, morbidity, and mortality rates}

We found that $93.0 \%$ (95\% CI 86.0 to 97.0 ) of patients who underwent $\mathrm{PAO}$ without bypass demonstrated complete or near complete occlusion of the aneurysm $>3$ months after the procedure compared with an occlusion rate of $67.0 \%(95 \% \mathrm{CI}$ 55.0 to 77.0$)$ in those who underwent endovascular coiling $(\mathrm{p}<0.01)$. The perioperative morbidity rate for endovascular coiling was $3.0 \%$ (95\% CI 2.0 to 6.0 ) compared with $7.0 \%$ (95\% CI 3.0 to 14.0$)$ for patients receiving PAO without bypass

Table 1 Description of studies

\begin{tabular}{|c|c|c|c|c|c|c|c|c|c|c|}
\hline Study & $\begin{array}{l}\text { No of } \\
\text { patients }\end{array}$ & $\begin{array}{l}\text { No of } \\
\text { aneurysms }\end{array}$ & $\begin{array}{l}\text { No of unruptured } \\
\text { aneurysms }\end{array}$ & CCF (n) & SAH (n) & $\begin{array}{l}\text { Carotid } \\
\text { occlusion (n) }\end{array}$ & $\begin{array}{l}\text { Aneurysm } \\
\text { coiling (n) }\end{array}$ & $\begin{array}{l}\text { Stent } \\
\text { assist (n) }\end{array}$ & $\begin{array}{l}\text { Mean follow-up } \\
\text { (months) }\end{array}$ & $\begin{array}{l}\text { Type of } \\
\text { study }\end{array}$ \\
\hline Murakami $^{25}$ & 7 & 7 & 6 & 1 & 0 & 7 & 0 & 0 & NA & $R$ \\
\hline Hauck $^{26}$ & 8 & 8 & 8 & 0 & 0 & 0 & 8 & 6 & 22 & $\mathrm{R}$ \\
\hline Suzuki ${ }^{27}$ & 10 & 11 & 11 & 0 & 0 & 0 & 11 & 0 & 58 & $R$ \\
\hline van Rooij ${ }^{10}$ & 85 & 86 & 77 & 8 & 1 & 55 & 31 & 2 & 42 & $R$ \\
\hline Morita $^{28}$ & 7 & 7 & 7 & 0 & 0 & 0 & 7 & 3 & 53 & $R$ \\
\hline Choulakian ${ }^{11}$ & 113 & 113 & 110 & 0 & 3 & 0 & 113 & 53 & 6 & $R$ \\
\hline $\mathrm{Akai}^{29}$ & 8 & 8 & 8 & 0 & 0 & 0 & 8 & 0 & 31 & $\mathrm{R}$ \\
\hline Elhammady ${ }^{19}$ & 15 & 15 & 14 & 0 & 1 & 15 & 0 & 0 & 14 & $R$ \\
\hline $\mathrm{Kim}^{20}$ & 19 & 19 & 18 & 0 & 1 & 0 & 19 & 0 & NA & $R$ \\
\hline Starke $e^{5}$ & 79 & 82 & 75 & 1 & 6 & 15 & 67 & 53 & 21 & $R$ \\
\hline Bavinzski $^{18}$ & 32 & 33 & 25 & 2 & 6 & 16 & 17 & 0 & 33 & $\mathrm{R}$ \\
\hline Barnett $^{30}$ & 6 & 6 & 5 & 0 & 1 & 6 & 0 & 0 & 6 & $R$ \\
\hline Kupersmith ${ }^{31}$ & 12 & 12 & 12 & 0 & 0 & 12 & 0 & 0 & 24 & $R$ \\
\hline Linskey $^{32}$ & 6 & 6 & 6 & 0 & 0 & 6 & 0 & 0 & 25 & $\mathrm{R}$ \\
\hline Lylyk ${ }^{33}$ & 60 & 60 & 40 & 0 & 0 & 40 & 0 & 0 & NA & $R$ \\
\hline Raymond ${ }^{34}$ & 7 & 7 & 7 & 0 & 0 & 7 & 0 & 0 & 4 & $R$ \\
\hline Halbach ${ }^{35}$ & 35 & 35 & 32 & 0 & 3 & 0 & 35 & 0 & NA & $R$ \\
\hline Weber $^{36}$ & 6 & 6 & 6 & 0 & 0 & 0 & 6 & 0 & 6 & $R$ \\
\hline Mawad $^{37}$ & 8 & 8 & 8 & 0 & 0 & 0 & 8 & 8 & 6 & $R$ \\
\hline Kono $^{38}$ & 6 & 6 & 6 & 0 & 0 & 0 & 6 & 6 & 16 & $R$ \\
\hline
\end{tabular}

CCF, carotid cavernous fistula; $R$, retrospective; $S A H$, subarachnoid hemorrhage; NA, not available. 
Table 2 Patient characteristics

\begin{tabular}{|c|c|c|c|}
\hline & $\begin{array}{l}\text { Meta-analysis } \\
(\%(95 \% \mathrm{CI}))\end{array}$ & $I^{2}(\%)$ & $\begin{array}{l}\text { Raw } \\
\text { numbers }\end{array}$ \\
\hline No of patients & - & - & 509 \\
\hline No of aneurysms treated & - & - & 515 \\
\hline \multicolumn{4}{|l|}{ Patient presentations } \\
\hline Cranial nerve deficit mass effect & $77.0(65.0$ to 86.0$)$ & 81 & $310 / 511$ \\
\hline SAH & $6.0(4.0$ to 9.0$)$ & 0 & $23 / 511$ \\
\hline $\mathrm{CCF}$ & 7.0 (5.0 to 9.0$)$ & 0 & $22 / 511$ \\
\hline \multicolumn{4}{|l|}{ Treatment modality } \\
\hline Carotid occlusion & $35.0(18.0$ to 58.0$)$ & 84 & $176 / 515$ \\
\hline Endovascular coiling & 65.0 (42.0 to 82.0$)$ & 84 & $339 / 515$ \\
\hline \multicolumn{4}{|l|}{ Cumulative outcomes } \\
\hline $\begin{array}{l}\text { Complete/near complete occlusion } \\
\text { at } 3 \text { months }\end{array}$ & $79.0(69.0$ to 87.0$)$ & 71 & $372 / 477$ \\
\hline Improvement in mass effect & $82.0(67.0$ to 91.0$)$ & 71 & $218 / 266$ \\
\hline Retreatment rate & $14.0(9.0$ to 21.0$)$ & 38 & $52 / 507$ \\
\hline Total periprocedural morbidity & $4.0(3.0$ to 7.0$)$ & 0 & $12 / 514$ \\
\hline Periprocedural stroke & $4.0(3.0$ to 6.0$)$ & 0 & $11 / 515$ \\
\hline Periprocedural hemorrhage & $3.0(2.0$ to 6.0$)$ & 0 & $2 / 515$ \\
\hline Periprocedural mortality & $3.0(2.0$ to 6.0$)$ & 0 & $2 / 515$ \\
\hline
\end{tabular}

$(\mathrm{p}=0.13)$. The perioperative mortality rate was $0.0 \%(95 \% \mathrm{CI}$ 0.0 to 6.0$)$ for endovascular coiling compared with $4.0 \%(95 \%$ CI 1.0 to 9.0$)$ for PAO without bypass $(p=0.68)$. The coiling group demonstrated a retreatment rate of $18.0 \%$ (95\% CI 12.0 to 26.0 ) compared with $6.0 \%$ (95\% CI 2.0 to 12.0 ) for PAO without bypass $(p=0.01)$. Improvement in mass effect/cranial nerve compressive symptoms was seen in $83.0 \%$ (95\% CI 52.0 to 96.0 ) of patients receiving PAO without bypass compared with $72.0 \%$ (95\% CI 48.0 to 87.0 ) of endosaccular coiling patients $(\mathrm{p}=0.48)$. These data are summarized in table 3 .

In a subgroup analysis of stent assisted versus non-stent assisted coiling, there were 76 patients with stent assisted coiling and 152 patients with non-stent assisted coiling. Patients receiving stent assisted coiling demonstrated a non-significant trend toward better occlusion rates $(56.0 \%, 95 \%$ CI 31.0 to 79.0$)$ compared with non-stent assisted coiling patients (45.0\%, 95\% CI 22.0 to 71.0$)(p=0.56)$. Retreatment rates were similar between the two groups, as stent assisted patients had a retreatment rate of $22.0 \%$ (95\% CI 14.0 to 33.0 ) compared with $20.0 \%$ (95\% CI 12.0 to 31.0$)(\mathrm{p}=0.80)$. Periprocedural morbidity was low in the stent assisted $(0.0 \%, 95 \%$ CI 0.0 to 21.0$)$ and non-stent assisted $(4.0 \%, 95 \%$ CI 2.0 to 9.0$)$ groups $(p=0.56)$. These data are summarized in table 4 .
A subgroup analysis of endovascular PAO with bypass found 41 patients. Occlusion rates were $93.0 \%$ (95\% CI 81.0 to 98.0 ). Total periprocedural morbidity was $11.0 \%$ (95\% CI 4.0 to 26.0) and total periprocedural mortality was $7.0 \%$ (95\% CI 2.0 to 19.0$)$. These data are summarized in table 5 .

\section{DISCUSSION}

Our systematic review of endovascular treatment of cavernous aneurysms demonstrated remarkably high rates of complete or near complete occlusion following PAO and substantially lower rates of such occlusion following either coil or stent-coil occlusion. The difference in occlusion between reconstructive and deconstructive techniques was not only statistically significant but also clinically relevant; this clinical relevance is further highlighted by a nearly three times higher rate of retreatment among the coil group compared with the PAO group. However, there was a trend towards significantly higher morbidity rates in the PAO compared with the coiling group. We noted a mortality rate of $4 \%$ in the former group and no mortality in the latter although this did not reach statistical significance. These findings indicate that the optimal therapy for patients suffering from symptomatic cavernous carotid aneurysms remains difficult to establish.

In a previous systematic review of outcomes of balloon occlusion and endosaccular coiling for treatment of cavernous carotid aneurysms, van der Schaaf et al found an ischemic complication rate of $5 \%$ for occlusion patients and a $0 \%$ complication rate for endovascular coiling patients. ${ }^{9}$ They also found a very high rate of long term aneurysmal occlusion in the parent artery embolization group of $97.5 \%$ compared with $80 \%$ in the coiling group. The study included 247 patients undergoing PAO (with and without bypass) and only 68 patients receiving endosaccular coiling. Our study differs from this previously published systematic review in that we only included patients with non-traumatic aneurysms and only compared outcomes of patients treated with endovascular techniques, excluding patients receiving $\mathrm{PAO}$ with bypass from statistical comparisons. Thus our patient population is more homogeneous, potentially allowing for more accurate comparisons between groups.

Other recently published large case series on the endovascular treatment of cavernous carotid aneurysms have demonstrated remarkably low complication rates with both PAO and endosaccular coiling. Van Rooij et al demonstrated a complication rate of $1.2 \%$ with PAO and $0.0 \%$ with endosaccular coiling. Similar to our study however, retreatment rates were significantly higher among endosaccular coiling patients compared with PAO patients. ${ }^{10}$ In a series of 113 patients receiving endosaccular

Table 3 Patient outcomes — coiling (combined stent assisted and non-stent assisted) versus parent artery occlusion without bypass

\begin{tabular}{|c|c|c|c|c|c|}
\hline & \multicolumn{2}{|l|}{ Endovascular coiling } & \multicolumn{2}{|l|}{ Endovascular PAO } & \multirow[b]{2}{*}{ p Value } \\
\hline & Meta-analysis (\% $(95 \% \mathrm{Cl}))$ & Raw numbers & Meta-analysis (\% $(95 \% \mathrm{Cl}))$ & Raw numbers & \\
\hline Complete/near complete occlusion at 3 months & $67.0(55.0$ to 77.0$)$ & 203/296 & $93.0(86.0$ to 97.0$)$ & $128 / 133$ & $<0.01$ \\
\hline Improvement in mass effect & 72.0 (48.0 to 87.0$)$ & $75 / 103$ & $83.0(52.0$ to 96.0$)$ & $63 / 76$ & 0.48 \\
\hline Retreatment rate & $18.0(12.0$ to 26.0$)$ & $49 / 333$ & $6.0(2.0$ to 12.0$)$ & $2 / 134$ & 0.01 \\
\hline Total periprocedural morbidity & $3.0(2.0$ to 6.0$)$ & $5 / 339$ & $7.0(3.0$ to 14.0$)$ & $5 / 135$ & 0.13 \\
\hline Periprocedural stroke & $3.0(2.0$ to 6.0$)$ & $4 / 339$ & $6.0(3.0$ to 12.0$)$ & $4 / 135$ & 0.31 \\
\hline Periprocedural hemorrhage & $3.0(1.0$ to 6.0$)$ & $1 / 339$ & $4.0(1.0$ to 9.0$)$ & $1 / 135$ & 0.68 \\
\hline Periprocedural mortality & $0.0(0.0$ to 6.0$)$ & $0 / 339$ & $4.0(1.0$ to 9.0$)$ & $1 / 135$ & 0.68 \\
\hline
\end{tabular}


Table 4 Patient characteristics—stent assisted coiling versus non-stent assisted coiling

\begin{tabular}{|c|c|c|c|c|c|}
\hline & \multicolumn{2}{|l|}{ Stent assisted coiling } & \multicolumn{2}{|l|}{ Non-stent assisted coiling } & \multirow[b]{2}{*}{ p Value } \\
\hline & Meta-analysis $(\%(95 \% \mathrm{CI}))$ & Raw numbers & Meta-analysis (\% $(95 \% \mathrm{Cl}))$ & Raw numbers & \\
\hline Complete/near complete occlusion at 3 months & 56.0 (31.0 to 79.0$)$ & $37 / 76$ & $45.0(22.0$ to 71.0$)$ & $59 / 109$ & 0.56 \\
\hline Improvement in mass effect & 44.0 (26.0 to 64.0$)$ & $13 / 28$ & 75.0 (49.0 to 90.0$)$ & $61 / 75$ & 0.06 \\
\hline Retreatment rate & $22.0(14.0$ to 33.0$)$ & $15 / 74$ & $20.0(12.0$ to 31.0$)$ & $21 / 152$ & 0.80 \\
\hline Total periprocedural morbidity & $0.0(0.0$ to 21.0$)$ & $0 / 74$ & $4.0(2.0$ to 9.0$)$ & $1 / 152$ & 0.68 \\
\hline Periprocedural stroke & $0.0(0.0$ to 21.0$)$ & $0 / 74$ & $0.0(0.0$ to 9.0$)$ & $0 / 152$ & 0.56 \\
\hline Periprocedural hemorrhage & $0.0(0.0$ to 21.0$)$ & $0 / 74$ & $4.0(2.0$ to 9.0$)$ & $1 / 152$ & 0.68 \\
\hline Periprocedural mortality & $0.0(0.0$ to 18.0$)$ & $0 / 74$ & $0.0(0.0$ to 9.0$)$ & $0 / 152$ & 0.56 \\
\hline
\end{tabular}

treatment for cavernous carotid aneurysms, Choulakian et al found a thromboembolic complication rate of $3.5 \%$ and a retreatment rate of $11.5 \%$, similar to our study. ${ }^{11}$

These current findings are very important as in the past few years flow diversion has been proposed as the treatment of choice in patients with aneurysms of the cavernous carotid artery. Larger studies examining outcomes of flow diverter treatment of cavernous carotid aneurysms demonstrated complete occlusion rates of $70-100 \%$ and symptom improvement in upwards of $90 \%$ of patients. ${ }^{12}$ However, flow diversion therapy is not devoid of important and often unpredictable complications, such as delayed aneurysm rupture and distal intraparenchymal hemorrhage. A meta-analysis performed by Brinjikji et al found procedure related morbidity and mortality rates of 5\% and $4 \%$, respectively, among all patients treated with flow diverters. Furthermore, they found an intraparenchymal hemorrhage rate of $3 \%$, and a stroke rate of $6 \% .^{13}$

Complications are perhaps less acceptable in the case of intracavernous aneurysms which may present with symptoms of mass effect and cranial neuropathy but generally have a more benign natural history than intradural aneurysms. Placement of a flow diverter requires the ability to cross the aneurysm neck with the microcatheter and microguidewire, and this may be particularly difficult in patients with very large and giant dysplastic intracavernous aneurysms. Many of these patients are elderly with diseased and tortuous vessels, which may increase the difficulty of the distal navigation. One of the advantages of flow diversion is that, unlike PAO, it allows for preservation of the parent artery while also allowing for very high rates of complete occlusion at follow-up. Indeed, in an analysis of practice changes since the introduction of flow diverters, we have observed a significant reduction in the rate of PAO since flow diverters become available. ${ }^{14} \mathrm{~A}$ potential shortcoming of PAO is the risk of developing aneurysms along the collateral pathways

Table 5 Outcomes of parent artery occlusion with extracranial to intracranial bypass

\begin{tabular}{lcc}
\hline & $\begin{array}{l}\text { Meta-analysis } \\
(\%(95 \% \text { Cl) }\end{array}$ & $\begin{array}{l}\text { Raw } \\
\text { numbers }\end{array}$ \\
\hline Complete/near complete occlusion at 3 months & $93.0(81.0$ to 98.0$)$ & $40 / 41$ \\
Improvement in mass effect & $87.0(57.0$ to 97.0$)$ & $30 / 33$ \\
Retreatment rate & $8.0(3.0$ to 22.0$)$ & $1 / 41$ \\
Total periprocedural morbidity & $11.0(4.0$ to 26.0$)$ & $3 / 41$ \\
Periprocedural stroke & $11.0(4.0$ to 26.0$)$ & $2 / 41$ \\
Periprocedural hemorrhage & $9.0(3.0$ to 24.0$)$ & $1 / 41$ \\
Periprocedural mortality & $7.0(2.0$ to 19.0$)$ & $1 / 41$ \\
\hline
\end{tabular}

in relation to the increased hemodynamic stress. ${ }^{15-17}$ This risk is theoretically higher in patients with intracavernous aneurysms as these patients often have dysplastic vessels and often already have mirror aneurysms on the contralateral carotid. ${ }^{15-17}$

With advances in endovascular techniques, a number of operators have tried to avoid PAO because of the above mentioned limitations in favor of reconstructive techniques such as flow diversion and/or endosaccular coil embolization with or without stent or balloon assistance. Our review suggests that endosaccular coiling can be conducted with a low complication rate with a trend suggesting rates lower than with PAO without bypass. Shortcomings of endosaccular occlusion include the lower rate of complete occlusion compared with $\mathrm{PAO}$ and the high recurrence rate, as many of these aneurysms are very large or giant and with wide necks. PAO alone may compare favorably with flow diversion in terms of complete occlusion rates and complications but the complication rates are likely much higher if bypass is needed. In this respect, after a period of over enthusiasm with flow diverters for symptomatic and expanding cavernous sinus aneurysms, our group now considers the use of PAO without bypass, especially in elderly patients or in cases where placing a flow diverter across the aneurysm neck may be difficult.

\section{Limitations}

Our study has several limitations. As noted above, the cases are likely highly selected, and our systematic review does not provide information on the exact proportion of all cavernous carotid aneurysms amenable to endovascular treatment. The data on which the systematic review are based may be affected by publication bias. It is possible that studies with favorable results are more likely to be published. Moreover, the limitations of single center experiences for potential complication under reporting are well known. Many details were lacking from the studies included in our analysis. For example, data on aneurysm size and geometry were not available in many studies. Assessment of geometric characteristics of intracranial aneurysms is an important factor in treatment decisions, such as whether or not to use adjunctive devices. Many studies did not stratify outcomes by aneurysm size and patient presentation (SAH, CCF, unruptured, etc), however, a vast majority of the patients in this study presented with unruptured aneurysms. An equal proportion of patients presented with CCF and SAH in our analysis, which may seem unexpected in a series of cavernous carotid aneurysms. However, among series reporting the size of cavernous carotid aneurysms causing SAH, all aneurysms were large or giant. ${ }^{11}{ }^{18-20}$ Furthermore, in the International Study of Unruptured Intracranial Aneurysms, large and giant cavernous carotid aneurysms had a 3.0\% and 6.4\% risk of SAH, respectively. $^{21}$ 
In addition, many of the series analyzed and reported in our analysis included cases collected over several years, and it is also possible that complication rates have improved as a result of increased operator experience and skill, and improved devices and technology. In general, many studies did not report why patients were treated with $\mathrm{PAO}$ versus coiling. However, most of the PAO patients included in our analysis were treated prior to the widespread utilization of endosaccular coiling. Factors such as personal preference and aneurysm size also contributed to the decision to perform PAO over coiling. ${ }^{19}$ Among the studies included in this meta-analysis, the decision to perform bypass in addition to PAO was based on the results of carotid occlusion tests. ${ }^{5} 10{ }^{18-20}$ If the occlusion test revealed non-tolerance, patients generally received bypass or conservative therapy. If coil modifications and flow diverter techniques prove to be safe and effective in preventing recurrences, the results reported in this systematic review will likely improve over time.

The comparisons reported in this meta-analysis were made across studies, not within studies, which greatly weakens inference. Using the Grading of Recommendations, Assessment, Development and Evaluation framework, the quality of evidence (confidence in estimates) was very low because of imprecision, heterogeneity, and methodological limitations of the included studies. ${ }^{22-24}$ Nevertheless, this meta-analysis provides useful data to share with patients and families when assessing the risks of treatment of cavernous carotid aneurysms, and represents a benchmark against which future studies, especially those on flow diverters, can be compared. With analysis of over 500 patients, this is currently the largest study examining outcomes of endovascular coiling of cavernous carotid aneurysms.

\section{CONCLUSION}

Carotid occlusion and endovascular coiling are both effective means for the treatment of cavernous carotid aneurysms. Non-comparative evidence suggests that endovascular carotid occlusion is associated with higher occlusion rates while endosaccular coiling is associated with slightly lower complication rates. Endovascular PAO paired with bypass is associated with high morbidity and mortality rates and should not be considered, except in select cases. Further research is needed to compare the efficacy of carotid occlusion, endosaccular coiling, and newer flow diverters in the treatment of cavernous carotid aneurysms.

Contributors All authors participated in drafting the article and revising it critically for important intellectual content. All authors made substantial contributions to conception and design, acquisition of the data, and analysis and interpretation of the data. All authors provided final approval of the version to be published.

Competing interests $\mathrm{HJC}$-grants/grants pending: Cordis Endovascular*. DFKconsultancy: ev3*, Medtronic ${ }^{*}$, and Codman ${ }^{*}$; grants/grants pending: ev $3^{*}$, MicroVention*, Sequent*, and Codman*; payment for lectures (including service on speakers bureaus): MicroVention*; royalties: UVA Patent Foundation*; payment for development of educational presentations: ev3*; travel/accommodations/meeting expenses unrelated to activities listed: MicroVention*. GL—consultancy: Edge Therapeutics; payment for development of educational presentations: Covidien/ev3*; travel/accommodations/meeting expenses unrelated to activities listed: Boston Biomedica Associates. *Money paid to institution.

Provenance and peer review Not commissioned; externally peer reviewed.

Data sharing statement The authors are willing to share spreadsheets from their data extraction on request.

\section{REFERENCES}

1 Kupersmith MJ, Hurst R, Berenstein A, et al. The benign course of cavernous carotid artery aneurysms. J Neurosurg 1992;77:690-3.

2 Kupersmith MJ, Stiebel-Kalish H, Huna-Baron R, et al. Cavernous carotid aneurysms rarely cause subarachnoid hemorrhage or major neurologic morbidity. I Stroke Cerebrovasc Dis 2002;11:9-14.
3 Stiebel-Kalish H, Kalish Y, Bar-On RH, et al. Presentation, natural history, and management of carotid cavernous aneurysms. Neurosurgery 2005;57:850-7.

4 Drazin D, Choulakian A, Nuno M, et al. Improvement in visual symptomatology after endovascular treatment of cavernous carotid aneurysms: a multicenter study. J Vasc Interv Neurol 2013;6:15-21.

5 Starke RM, Chalouhi N, Ali MS, et al. Endovascular treatment of carotid cavernous aneurysms: complications, outcomes and comparison of interventional strategies. J Clin Neurosci 2014;21:40-6.

6 DerSimonian R, Laird N. Meta-analysis in clinical trials. Control Clin Trials 1986;7:177-88

7 Altman DG, Bland JM. Interaction revisited: the difference between two estimates. BMJ 2003;326:219.

8 Higgins JP, Thompson SG, Deeks JJ, et al. Measuring inconsistency in meta-analyses. BMJ 2003;327:557-60.

9 van der Schaaf IC, Brilstra EH, Buskens E, et al. Endovascular treatment of aneurysms in the cavernous sinus: a systematic review on balloon occlusion of the parent vessel and embolization with coils. Stroke 2002;33:313-18.

10 van Rooij WJ. Endovascular treatment of cavernous sinus aneurysms. AJNR Am J Neuroradiol 2012;33:323-6.

11 Choulakian A, Drazin D, Alexander MJ. Endosaccular treatment of 113 cavernous carotid artery aneurysms. J Neurointerv Surg 2010;2:359-62.

12 O'Kelly CJ, Spears J, Chow M, et al. Canadian experience with the pipeline embolization device for repair of unruptured intracranial aneurysms. AJNR Am J Neuroradiol 2013;34:381-7.

13 Brinjikji W, Murad MH, Lanzino G, et al. Endovascular treatment of intracranial aneurysms with flow diverters: a meta-analysis. Stroke 2013;44:442-7.

14 Lanzino G, Crobeddu E, Cloft HJ, et al. Efficacy and safety of flow diversion for paraclinoid aneurysms: a matched-pair analysis compared with standard endovascular approaches. AJNR Am J Neuroradiol 2012;33:2158-61.

15 Arambepola PK, McEvoy SD, Bulsara KR. De novo aneurysm formation after carotid artery occlusion for cerebral aneurysms. Skull Base 2010;20:405-8.

16 Arnaout OM, Rahme RJ, Aoun SG, et al. De novo large fusiform posterior circulation intracranial aneurysm presenting with subarachnoid hemorrhage 7 years after therapeutic internal carotid artery occlusion: case report and review of the literature. Neurosurgery 2012;71:E764-71.

17 Tomsick T. Long-term clinical follow-up of therapeutic internal carotid artery occlusion. AJNR Am J Neuroradiol 2007;28:1626.

18 Bavinzski G, Killer M, Ferraz-Leite $H$, et al. Endovascular therapy of idiopathic cavernous aneurysms over 11 years. AJNR Am J Neuroradiol 1998;19:559-65.

19 Elhammady MS, Wolfe SQ, Farhat H, et al. Carotid artery sacrifice for unclippable and uncoilable aneurysms: endovascular occlusion vs common carotid artery ligation. Neurosurgery 2010;67:1431-6.

20 Kim SJ, Choi IS. GDC embolisation of cavernous internal carotid artery aneurysms with parent artery preservation. Interv Neuroradiol 2000;6:291-8.

21 Wiebers DO, Whisnant JP, Huston J III, et al. Unruptured intracranial aneurysms: natural history, clinical outcome, and risks of surgical and endovascular treatment. Lancet 2003:362:103-10.

22 Balshem $H$, Helfand $M$, Schunemann $H J$, et al. GRADE guidelines: 3. Rating the quality of evidence. J Clin Epidemiol 2011;64:401-6.

23 Guyatt GH, Oxman AD, Kunz R, et al. GRADE guidelines 6 . Rating the quality of evidence-imprecision. J Clin Epidemiol 2011;64:1283-93.

24 Murad MH, Swiglo BA, Sidawy AN, et al. Methodology for clinical practice guidelines for the management of arteriovenous access. J Vasc Surg 2008;48(5 Suppl):26S-30S

25 Murakami K, Shimizu H, Matsumoto $Y$, et al. Acute ischemic complications after therapeutic parent artery occlusion with revascularization for complex internal carotid artery aneurysms. Surg Neurol 2009;71:434-41.

26 Hauck EF, Welch BG, White JA, et al. Stent/coil treatment of very large and giant unruptured ophthalmic and cavernous aneurysms. Surg Neurol 2009;71:19-24.

27 Suzuki S, Kurata A, Kan S, et al. Efficacy of endovascular surgery for unruptured internal carotid artery aneurysms presenting with cranial nerve symptoms. InterV Neuroradiol 2007;13(Suppl 1):163-9.

28 Morita K, Sorimachi T, Ito Y, et al. Intra-aneurysmal coil embolization for large or giant carotid artery aneurysms in the cavernous sinus. Neurol Med Chir (Tokyo) 2011:51:762-6.

29 Akai F, Nakagawa S, Fukawa T, et al. Symptomatic cavernous internal carotid artery aneurysms treated with detachable coils. Interv Neuroradiol 2003;9(Suppl 1):89-94.

30 Barnett DW, Barrow DL, Joseph GJ. Combined extracranial-intracranial bypass and intraoperative balloon occlusion for the treatment of intracavernous and proximal carotid artery aneurysms. Neurosurgery 1994;35:92-7.

31 Kupersmith MJ, Berenstein A, Choi IS, et al. Percutaneous transvascular treatment of giant carotid aneurysms: neuro-ophthalmologic findings. Neurology 1984;34:328-35

32 Linskey ME, Sekhar LN, Horton JA, et al. Aneurysms of the intracavernous carotid artery: a multidisciplinary approach to treatment. J Neurosurg 1991;75:525-34. 
33 Lylyk P, Vinuela F, Campos J, et al. Diagnosis and endovascular therapy of vascular lesions in the cavernous sinus. Acta Radiol Suppl 1986;369:584-5.

34 Raymond J, Theron J. Intracavernous aneurysms: treatment by proximal balloon occlusion of the internal carotid artery. AJNR Am J Neuroradiol 1986;7:1087-92.

35 Halbach VV, Higashida RT, Dowd CF, et al. Cavernous internal carotid artery aneurysms treated with electrolytically detachable coils. I Neuroophthalmol 1997;17:231-9.
36 Weber W, Siekmann R, Kis B, et al. Treatment and follow-up of 22 unruptured wide-necked intracranial aneurysms of the internal carotid artery with Onyx HD 500. AJNR Am J Neuroradiol 2005;26:1909-15.

37 Mawad ME, Cekirge S, Ciceri E, et al. Endovascular treatment of giant and large intracranial aneurysms by using a combination of stent placement and liquid polymer injection. J Neurosurg. 2002;96:474-82.

38 Kono K, Shintani A, Okada H, et al. Stent-assisted coil embolization for cavernous carotid artery aneurysms. Neurol Med Chir (Tokyo) 2014;54:126-32.

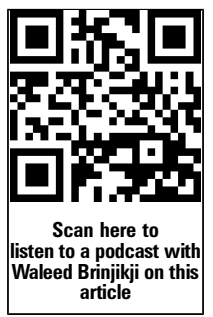

